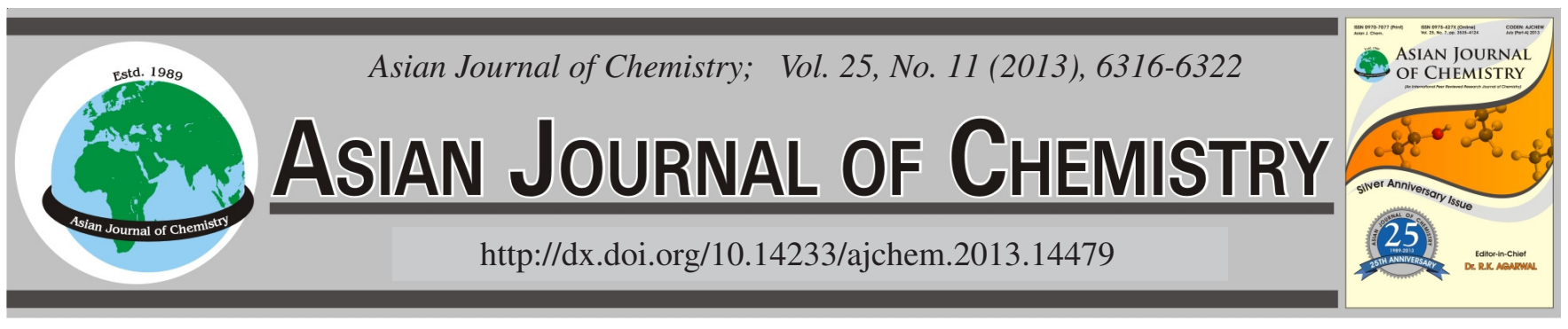

\title{
Response Surface Optimization of Ultrasonic-Assisted Oil-Conjugated Reaction Using Solid Nickel Catalyst
}

\author{
YANG RI-Fu ${ }^{1, *}$, DENG QI-QI ${ }^{1}$ and YAN JIE ${ }^{2}$
}

${ }^{1}$ College of Science, South China University of Technology, Guangzhou 510641, P.R. China

${ }^{2}$ College of Chemistry and Chemical Engineering, Zhongkai University of Agriculture and Engineering, Guangzhou 510225, P.R. China

*Corresponding author: Fax: +86 20 87113308; Tel: +86 20 87113783; E-mail: yangrifu@ scut.edu.cn; 641540748@qq.com

(Received: 25 August 2012;

Accepted: 8 May 2013)

AJC-13463

\begin{abstract}
The effect of ultrasonic irradiation on oil-conjugated reaction using solid catalyst has been investigated. Through single factor tests and response surface methodology (RSM), batch processes assisted with $20 \mathrm{kHz}$ ultrasound were performed to study the impacts of ultrasonic power, temperature, catalyst loading and reaction time on the content of conjugated linoleic acid. The multivariate analysis results indicated that the optimum reaction conditions were ultrasonic power of $240 \mathrm{~W}$, temperature of $180^{\circ} \mathrm{C}$, catalyst loading of $8 \mathrm{wt} . \%$ and reaction time of $1 \mathrm{~h}$, at which the highest product yield of $4.644 \mathrm{mg} / \mathrm{mL}$ was achieved. Reaction time was found to exert the most significant weight on the variability of the conjugated linoleic acid concentration, followed by system temperature. In the present research, the resultant content under ultrasonic cavitation realized an adequate raise, compared with the conventional magnetic stirring reactor.
\end{abstract}

Key Words: Ultrasonic irradiation, Solid catalyst, Oil-conjugated reaction, Conjugated linoleic acid, Response surface methodology.

\section{INTRODUCTION}

Conjugated linoleic acid (CLA) refers to a generic term for several positional and geometrical isomers of octadecadienoic fatty acid molecules with conjugated double bonds. Recently, conjugated linoleic acid attracted widespread attention due to its various beneficial and therapeutic functions. It has been confirmed by considerable researches that conjugated linoleic acid has multitudes of biological activities, e.g., anticarcinogenic effects, suppressing tumor development, reducing internal fat deposition, restraining atherosclerosis, enhancing immunity, decreasing cholesterol level and stimulating body growth. In addition, conjugated linoleic acid, as a food additive, can effectively improve the quality of meat and inhibit mold growth ${ }^{1-5}$. Undoubtedly, conjugated linoleic acid shows an extensive application prospect in medicine, health products, food technology and other fields.

The frequent synthetic approach for producing conjugated linoleic acid is oil-conjugated reaction, an isomerization process where vegetable oil rich in linoleic acid reacts to generate conjugated linoleic acid in the presence of base or acid catalysts or biological enzymes ${ }^{6-8}$. There have been large numbers of studies conducted to investigate the production of conjugated linoleic acid. Regarding biosynthesis, for instance, Bifidobacterium breve DPC6330 has been reported the ability to bio-convert $70 \%$ of the linoleic acid to conjugated linoleic acid, making it an extremely effective conjugated fatty acid producer $^{7}$. However, certain drawbacks, such as the high production cost and poor reusability of bio-enzymes, act as an obstacle for the large-scale industrialization of conjugated linoleic acid biosynthesis. In terms of chemical methods, the oil-conjugated reaction is conventionally carried out at a high temperature using a homogeneous basic catalyst ${ }^{9}$. This traditional technique, though embodying fast reaction rate and favorable conversion, involves high energy consumption, indispensable neutralization and abstersion treatments of resultants after reaction. Moreover, it is not supposed to be ignored that the generation of huge amounts of wastewater during the reaction process, which poses an ecological threat and the difficult separation of the product from homogeneous reaction system. In contrast, the heterogeneous catalytic process reduces the cost and minimizes the environmental impacts by reason of its milder reaction conditions, simpler test steps and easier catalyst recycling. Consequently, solid catalysts are expected to be the latest generation of environmentally benign catalytic materials ${ }^{10,11}$.

Nevertheless, the critical issue associated with the heterogeneous catalysis lies in its lower reaction speed owing to the weak interaction between oils and solid catalysts, originating from their mutual immiscibility. The introduction of continuous and vigorous mixing is thus necessary for increasing 
the interfacial region between these two phases. An alternative means of enhancing the mixing action is the application of low frequency ultrasound, which is theoretically treated as an efficient, energy saving and economically viable way to accelerate the conjugated reaction of oil molecules. Ultrasonic irradiation contributes to an enormous advancement of the contact surface through the acoustic energy propagation. The most crucial phenomenon of ultrasonic transmission in liquid is considered to be the cavitation effect. The collapse of innumerable cavitation bubbles is responsible for the formation of intense shock waves and plentiful extreme micro areas with high temperature and high pressure, which is in favour of improving reaction conditions, quickening reaction rate and boosting resultant conversion ${ }^{12-15}$.

The combined use of power ultrasound and heterogeneous catalyst has been documented to achieve noticeable successes in the chemosynthesis domain. Under ultrasonic irradiation, the transesterification of Jatropha curcus oil with methanol in the presence of solid catalyst, $\mathrm{Na} / \mathrm{SiO}_{2}$, was performed to produce biodiesel, of which the greatest conversion achieved was $98.47 \%^{16}$. When $\mathrm{BaO}$ was applied as a heterogeneous alkaline catalyst, the conversion rate of biodiesel was up to $95.5 \%$ in the ultrasonic reactor ${ }^{17}$. Despite these findings, the promotion effect of ultrasonic energy combined with solid catalyst on the oil-conjugated reaction has barely been found in the literature. Therefore, the present study conducted this practical method, i.e., the combination of ultrasound and solid catalyst, to increase the conjugated linoleic acid concentration. Furthermore, a series of comparative experiments, oil-conjugated reactions with and without ultrasonic irradiation, have been carried out to quantitatively illustrate the ultrasound-enhanced effect on the conjugated linoleic acid synthesis. The increased conjugated linoleic acid yield in the ultrasonic reactor, under different conditions, could be accurately calculated with real and reliable experimental data.

The processing of measured data was previously grounded on the one-factor-at-a-time approach, where reciprocal interactions between influential variables are obviously not taken into account. Hence, the analysis of experimental outcomes most likely leads to an incorrect prediction for optimum reaction conditions ${ }^{18}$. Experimental design methods are currently of increasing interest. Response surface methodology (RSM) is one of the most powerful multivariate analysis tools employed to optimize the multifactor experiment, establish the mathematical model and evaluate the impact of various control factors and their mutual interactions on the process response ${ }^{19-21}$. Respective result analyses of single factor tests and response surface experiments have been performed in this investigation, providing better insight into the variability of the product yield for different parameter combinations. Meanwhile, the selected ranges of independent variables for RSM could be scientifically interpreted from the trends of single factor experimental curves.

The primary objective of this research is to determine the optimum conditions and the corresponding maximum yield for the oil-conjugated reaction, as well as to characterize the influences of ultrasonic power, temperature, reaction time and catalyst loading on the overall process behaviour.

\section{EXPERIMENTAL}

The crude oil used in the conjugated reaction was Golden Dragon Fish soybean oil. The solid catalyst, nickel powder, was supplied from Tianjin Damao Chemical Reagent Factory. The conjugated linoleic acid Standard substance was purchased from Nu-Chek-Prep, Inc. The $n$-hexane was obtained from Guangdong Guanghua Sci-tech Co., Ltd.

The JY92-flultrasonic cell crusher, used to generate ultrasonic waves in the reaction system, was purchased from Ningbo Scientz Biotechnology Co., Ltd. The SZCL-3A intelligent digital magnetic stirrer was supplied from Yuhua Instrument Co., Ltd., in Gongyi City. The UV-5200 spectrophotometer, manufactured by Shanghai Metash Instrument Co., Ltd., was employed to measure the absorbance of conjugated linoleic acid. Nitrogen cylinders, from which the high purity carrier gas was obtained, was purchased from Guangzhou Geoge Gases Co., Ltd. The graphical representation of the experiment installing for the conjugated linoleic acid production process is presented in Fig. 1.

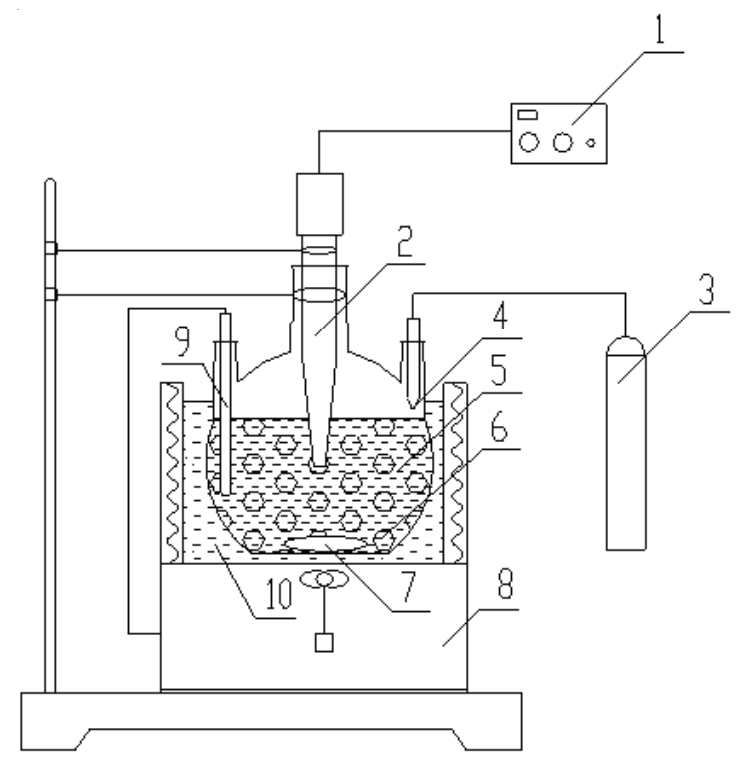

Fig. 1. Schematic diagram of the experimental apparatus for oil-conjugated reaction. 1. Ultrasonic cell crusher; 2. Sonotrode; 3. Nitrogen cylinder; 4. Carrier gas entrance; 5 . Soybean oil; 6. Nickel catalyst; 7. Stir bar; 8. Intelligent digital magnetic stirrer; 9. Temperature sensor; 10. Heat transfer oil

Procedure of oil-conjugated reaction: The oil-conjugated reaction was performed in a three-neck flask placed in a magnetic stirrer with a constant temperature oil bath. A volume of $40 \mathrm{~mL}$ of soybean oil, placed in this flask, was stirred and heated under the protection of high purity nitrogen. The catalyst loading needed was determined according to experimental requirements. An appropriate amount of nickel catalyst was added to the precisely prepared soybean oil when the temperature of the oil was slightly higher than the target temperature. The ultrasound generator was then introduced to this mixture. After the desired irradiation time, which varied from 20 to 120 min, the mixed solution was filtered for the separation of the catalyst with a vacuum pump. The final product was collected in $10 \mathrm{~mL}$ test tubes. Eventually, the yield of conjugated linoleic acid was measured using a spectrophotometer. 
Measurement of the conjugated linoleic acid concentration: There have already been several reported methods on measuring the conjugated linoleic acid content, including infrared spectroscopic measurements, gas chromatography, gas chromatography-mass spectroscopy, high-performance liquid chromatography and ultraviolet-visible spectroscopy. UVvisible spectroscopy refers to the absorption or reflectance spectroscopy in the ultraviolet-visible spectral region. In this region, conjugated double bonds in oil molecules exhibited the maximum absorption of strong ultraviolet radiation, for which the wavelength is $c a .233-234 \mathrm{~nm}$. The more conjugated double bonds formed in the oil, the higher the absorbance value would be. This means that the absorbance of oil is directly proportional to the conjugated linoleic acid concentration in the oil. On the basis of the above concept, ultraviolet-visible spectroscopy can be employed for the quantitative measurement of conjugated linoleic acid concentration. Accordingly, it is necessary to know the variation law of absorbance with the conjugated linoleic acid content. This relationship could be accurately determined from the calibration curve equation. The conjugated linoleic acid yield was then able to be calculated from eqn. 1 below,

$$
\mathrm{Y}=\frac{\mathrm{M}-\mathrm{M}_{0}}{\mathrm{~V}} \times 100 \%
$$

where $\mathrm{Y}$ is the yield rate of conjugated linoleic acid $(\mathrm{mg} / \mathrm{mL})$; $\mathrm{M}$ is the total mass of conjugated linoleic acid after reaction and $\mathrm{M}_{0}$ is the initial mass of conjugated linoleic acid in the crude oil. $\mathrm{V}$ is the volume of crude oil $(40 \mathrm{~mL})$, which remained constant during the process.

Formulation of the calibration curve equation: A mass of $0.4343 \mathrm{~g}$ of conjugated linoleic acid standard substance was dissolved in a $1000 \mathrm{~mL}$ volumetric flask with the $n$ hexane. Varying amounts of this mixture $(20,50,70,100,150$, 200 and $250 \mu \mathrm{L}$ ) were extracted and subsequently diluted in individual $10 \mathrm{~mL}$ measuring flasks with $n$-hexane. By comparing the absorbance of $n$-hexane, the absorbance of these mixed solutions could be determined at an ultraviolet wavelength of $234 \mathrm{~nm}$. Each absorbance value obtained was the average of three repeated measurements. The calibration curve of the absorbance versus the concentration was then established according to all of the seven observed values. The calibration curve equation obtained via linear fitting was $\mathrm{Y}=0.01216+$ 9.78126X, where $\mathrm{X}$ is the absorbance; $\mathrm{Y}$ is the corresponding concentration of conjugated linoleic acid $(\mathrm{mg} / \mathrm{mL})$ and the error $\mathrm{R}^{2}$ is equal to 0.9993 .

Application of the RSM: For the optimization of the ultrasound-enhanced oil-conjugated reaction in the presence of solid catalyst, a three-level-four-factor Box-Behnken design (BBD) was utilized to determine the best combination of experimental variables, including temperature (A), ultrasonic power (B), reaction time (C) and catalyst loading (D). Each experimental set was performed in triplicate and all the data used in the regression analysis were an average of the triplicate measurements. A total of 29 experimental runs were designed, of which 24 were unique combinations of parameters and 5 were repetitions. These 5 replicates were used to evaluate the pure error and experimental reproducibility. It was assumed that an empirical second-order regression model could be used to depict the relationship between the response and control variables. Thus, the general quadratic polynomial model for predicting the optimal values would be described by eqn. 2 ,

$$
Y=\beta_{0}+\sum_{i=1}^{4} \beta_{j} X_{i}+\sum_{j=1}^{4} \beta_{j j} x_{i}^{2}+\sum_{i=1}^{3} \sum_{j=i+1}^{4} \beta_{i j} X_{i} X_{j}+\varepsilon
$$

where $\mathrm{Y}$ is the predicted response (the yield of conjugated linoleic acid); $b_{0}, b_{j}, b_{j j}$ and $b_{i j}$ are the regression coefficients for intercept, linearity, square and interaction, respectively; $\mathrm{X}_{\mathrm{i}}$ and $\mathrm{X}_{\mathrm{j}}$ are influential factors (independent variables) and $\mathrm{e}$ is the random error.

Design Expert software (Version 8.0.4) was employed to perform analysis of variance (ANOVA), generate response surfaces and estimate optimum reaction conditions. The suitability of the developed polynomial model was inspected based on the coefficient of determination $\left(\mathrm{R}^{2}\right)$. The significance of the terms in the model equation was tested using $\mathrm{F}^{-}$value and $p$-value. Only when the ANOVA results display a high level of statistical significance, with F-value within $95 \%$ level of confidence and $p$-value $<0.05$, is the quadratic regression analysis model regarded advisable. Using the fitted model, response surface and contour plots were established for each pair of control variables while maintaining the other two variables at constant values, which facilitated the precise stimulation of the oil-conjugated reaction under all conditions.

\section{RESULTS AND DISCUSSION}

\section{Single factor tests}

Effect of ultrasonic power: Fig. 2 discloses the variation of the conjugated linoleic acid yield with ultrasonic power, which varied within a range of $80-400 \mathrm{~W}$ with intervals of 80 $\mathrm{W}$. The frequency of ultrasound applied was $20 \mathrm{kHz}$. The developed relation curve apparently falls into two diverse areas. The content of conjugated linoleic acid rocketed as ultrasonic irradiation mounted from $80-160 \mathrm{~W}$ in the first area. The highest yield of $1.791 \mathrm{mg} / \mathrm{mL}$ was recorded using $160 \mathrm{~W}$ of acoustic power. In the second area, where ultrasonic power ranged from 160 to $400 \mathrm{~W}$, there was a continuous decrease in the product conversion with the increase in output power. This phenomenon may have arisen for several reasons. First, an excess of ultrasonic power was responsible for generating multitudes of cavitation bubbles in the oil. Many of these bubbles coalesced to form larger and longer-lived ones, which were bound to hamper the transfer of ultrasonic energy through the liquid by reflection and scattering effects ${ }^{22}$. Secondly, under high power conditions, cavitation bubbles may grow so large during rarefaction that the time available for collapse is insufficient in the compression half cycle. The resultant cavitational effects would therefore be weaker at higher output power ${ }^{23}$. As seen in Fig. 2, the most suitable range of ultrasonic power for RSM experimental design was $80-240 \mathrm{~W}$.

Effect of temperature: Fig. 3 indicates the effect of temperature on the oil-conjugated reaction under two different conditions, including with and without ultrasonic oscillations. On average, the formation amount of conjugated linoleic acid under ultrasonic irradiation exceeded that under conventional 


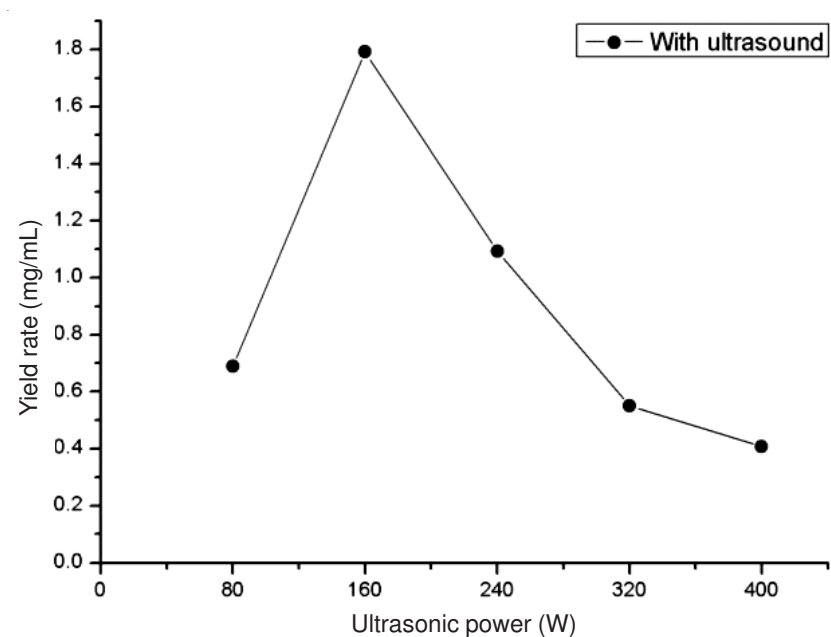

Fig. 2. Effect of ultrasonic power on oil-conjugated reaction with catalyst loading $10 \mathrm{wt}$. $\%$, temperature $120^{\circ} \mathrm{C}$ and reaction time $40 \mathrm{~min}$

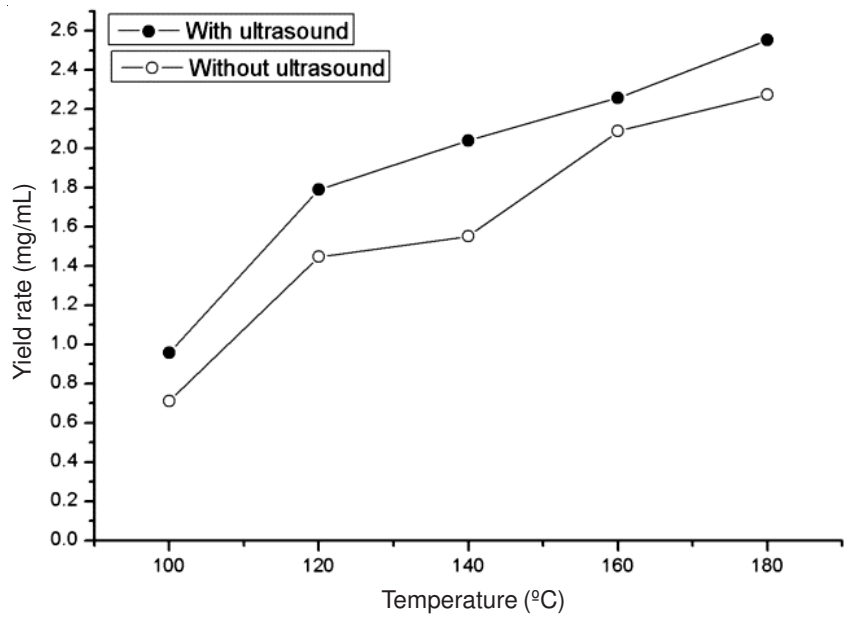

Fig. 3. Effect of temperature on the oil-conjugated reaction with catalyst loading $10 \mathrm{wt} \%$, ultrasonic power $160 \mathrm{~W}$ and reaction time 40 $\min$

magnetic stirring by $28 \%$. As shown in this graph, the conversion of conjugated linoleic acid soared as the system temperature rose. The yield rate of conjugated linoleic acid with ultrasonic irradiation reached its upper limit value of 2.551 $\mathrm{mg} / \mathrm{mL}$ when the temperature was $180{ }^{\circ} \mathrm{C}$. For the sake of saving energy and avoiding the occurrence of possible side reactions due to overheating, none of the oil-conjugated reactions in this study was performed at a temperature beyond $180{ }^{\circ} \mathrm{C}$. The temperature range of $140-180{ }^{\circ} \mathrm{C}$ was reckoned to be optimal for further multifactor experiments.

Effect of reaction time: The relationship between the product concentration and reaction time is demonstrated in Fig. 4. The conjugated linoleic acid yield under ultrasonic action was, on average, $60 \%$ higher than that under magnetic stirring. As the reaction time varied between 20 and $60 \mathrm{~min}$ with an interval of $10 \mathrm{~min}$, the greatest conjugated linoleic acid production of $c a .2 .3 \mathrm{mg} / \mathrm{mL}$ could be achieved at $1 \mathrm{~h}$ using ultrasonic energy. Nonetheless, the conversion of conjugated linoleic acid experienced a constant decline as the reaction time increased from 1 to $2 \mathrm{~h}$. These shapes of two different curves, with maxima, could be interpreted by the active and unstable chemical properties of conjugated linoleic

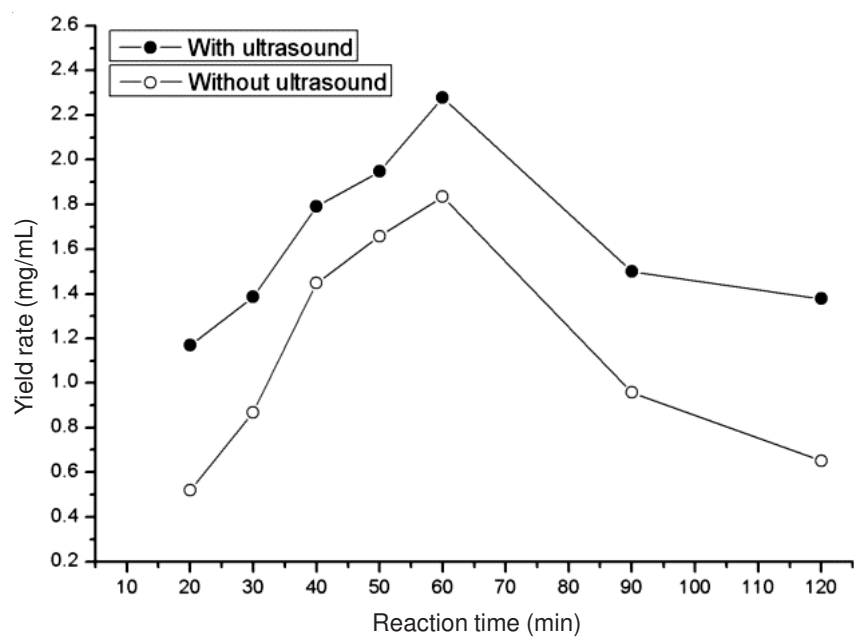

Fig. 4. Effect of reaction time on the oil-conjugated reaction with catalyst loading $10 \mathrm{wt}$ \% , ultrasonic power $160 \mathrm{~W}$ and temperature $120^{\circ} \mathrm{C}$

acid molecules, of which the oxidation and polymerization reaction was likely to occur under prolonged reaction durations. As a result, this would give rise to the raise in byproducts, the fall in resultant quality and the sharp decrease in the conjugated linoleic acid yield rate. Unquestionably, the reaction duration should be limited to $1 \mathrm{~h}$. The reaction time within the scope of 40-60 min was favorable for producing higher conjugated linoleic acid content and thus chosen for the response surface design.

Effect of catalyst loading: The impact of diverse mass ratios of catalyst on the generation rate of conjugated linoleic acid is revealed in Fig. 5. From this figure, it could be deduced that there was an average increase of $109 \%$ in the yield of conjugated linoleic acid in the ultrasonic-assisted reactor versus in the mechanical stirring system under the same reaction conditions. The formation of conjugated linoleic acid was accelerated with the weight $\%$ of catalyst to oil climbing from 4 to $10 \%$ and the highest conjugated linoleic acid production of $1.791 \mathrm{mg} / \mathrm{mL}$ was attained at $10 \mathrm{wt}$. \%, i.e., $3.410 \mathrm{~g}$. At catalyst loadings above $10 \mathrm{wt} . \%$, however, there was a rapid decline in the concentration of conjugated linoleic acid. This observed consequence illustrates that the catalyst quantity

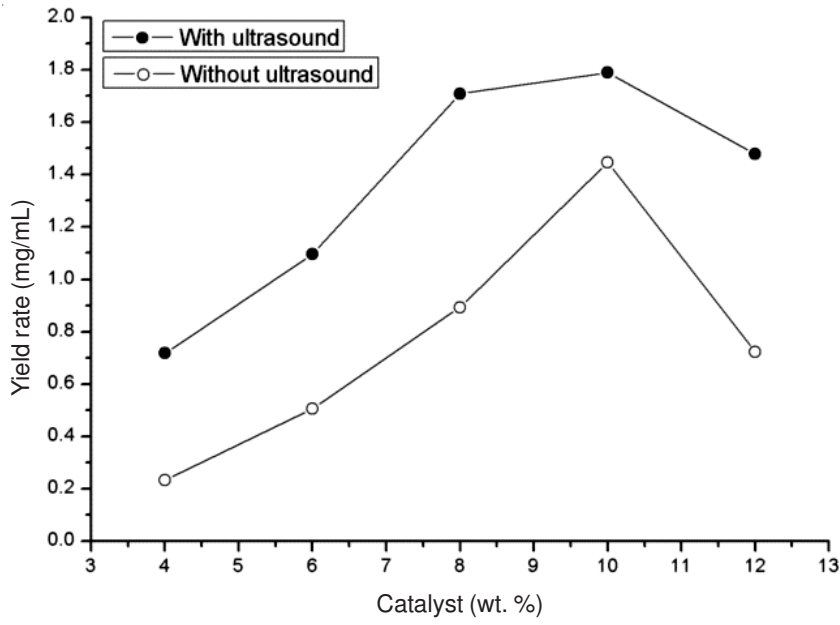

Fig. 5. Effect of catalyst loading on the oil-conjugated reaction with reaction time $40 \mathrm{~min}$, ultrasonic power $160 \mathrm{~W}$ and temperature $120^{\circ} \mathrm{C}$ 
rising towards 10 wt. \% could immensely boost the contact between the reactant and the catalyst. Nevertheless, excessive use of catalyst would certainly serve as a hindrance for effective collisions among the oil molecules, bringing about the intense drop in the conjugated linoleic acid yield. Hence, the catalyst loading should be appropriately selected to avoid unnecessary waste. Moreover, the optimal range of catalyst loading for the further research was deemed to be $8-12 \mathrm{wt}$. $\%$.

\section{Results and analyses of BBD experiments}

Predicted model and the ANOVA: The three design levels of each parameter were selected according to the results of the above mentioned single factor tests. Table- 1 tabulates the ranges and levels of influential variables investigated in the response surface design, which were assigned to three levels, namely, low (-1), mean (0) and high (+1).

\begin{tabular}{lcccc}
\multicolumn{5}{c}{ TABLE-1 } \\
LEVELS OF THE INDEPENDENT VARIABLES \\
\hline \multirow{2}{*}{ Factor } & \multirow{2}{*}{ Coding } & \multicolumn{3}{c}{ Levels } \\
\cline { 3 - 5 } & & -1 & 0 & 1 \\
\hline Temperature $\left({ }^{\circ} \mathrm{C}\right.$ ) & $\mathrm{A}$ & 140 & 160 & 180 \\
Ultrasonic power (W) & $\mathrm{B}$ & 80 & 160 & 240 \\
Reaction time (min) & $\mathrm{C}$ & 40 & 50 & 60 \\
Catalyst loading (wt \%) & $\mathrm{D}$ & 8 & 10 & 12 \\
\hline
\end{tabular}

By virtue of multiple regression analysis on the experimental data, the empirical polynomial model for estimating the response value was deduced as follows (based on coded values):
$\mathrm{Y}=1.81+0.44 \mathrm{~A}-0.085 \mathrm{~B}+0.51 \mathrm{C}-0.068 \mathrm{D}+0.27 \mathrm{AB}+$ $0.38 \mathrm{AC}+0.17 \mathrm{AD}-0.15 \mathrm{BC}-0.13 \mathrm{BD}-0.33 \mathrm{CD}+0.34 \mathrm{~A}^{2}+$ $0.26 \mathrm{~B}^{2}+0.50 \mathrm{C}^{2}+0.32 \mathrm{D}^{2}$

where $\mathrm{Y}$ is the dependent variable (the conjugated linoleic acid yield) and A, B, C and D are the coded values of the control variables (i.e., temperature, ultrasonic power, reaction time and catalyst loading, respectively). Table- 2 reports the measured value for each experimental run and the relevant predicted outcome calculated with eqn. 3 , which reflects a favoured correlation between the two.

The test data were examined by the ANOVA to assess the significance and adequacy of the quadratic model and to evaluate the effect of various terms in the equation on the response parameter. The ANOVA results for the predicted mathematical model are listed in Table-3.

As delineated in Table-3, at a confidence level of $95 \%$, the $p$-value (probability of error value) of the model was 0.0003, which demonstrated that the selected model precisely predicted the conjugated linoleic acid yield within the scope of the process factors and was valid for the current research. The model F-value of 7.3977 implied that this model was significant, with only a $0.03 \%$ chance that a model F-value this large could occur due to noise.

The suitability of the fitted model was evaluated based on the coefficient of determination $\left(\mathrm{R}^{2}\right)$, of which the magnitude portrays the aptness of developed model. The $\mathrm{R}^{2}$ value was calculated to be 0.88 in this study, revealing that the suggested model reliably predicted the experimental results and sufficiently

\begin{tabular}{|c|c|c|c|c|c|c|}
\hline \multirow{3}{*}{ Runs } & \multicolumn{5}{|c|}{$\begin{array}{c}\text { TABLE-2 } \\
\text { RESPONSE SURFACE EXPERIMENTAL DESIGN AND RESULTS }\end{array}$} & \\
\hline & \multirow{2}{*}{$\frac{\text { Temp }\left({ }^{\circ} \mathrm{C}\right)}{\mathrm{A}}$} & \multirow{2}{*}{$\frac{\text { Ultrasonic power }(\mathrm{W})}{\mathrm{B}}$} & \multirow{2}{*}{$\frac{\text { Reaction time }(\min )}{\mathrm{C}}$} & \multirow{2}{*}{$\frac{\text { Catalyst loading (wt. \%) }}{\text { D }}$} & \multicolumn{2}{|c|}{ Yield rate $(\mathrm{mg} / \mathrm{mL})$} \\
\hline & & & & & Experimental & Predicted \\
\hline 1 & 140 & 160 & 40 & 10 & 2.042 & 2.080 \\
\hline 2 & 140 & 160 & 50 & 12 & 2.058 & 1.793 \\
\hline 3 & 140 & 160 & 50 & 8 & 2.462 & 2.261 \\
\hline 4 & 140 & 160 & 60 & 10 & 2.070 & 2.331 \\
\hline 5 & 140 & 80 & 50 & 10 & 1.968 & 2.324 \\
\hline 6 & 140 & 240 & 50 & 10 & 1.801 & 1.608 \\
\hline 7 & 160 & 160 & 50 & 10 & 1.810 & 1.809 \\
\hline 8 & 160 & 160 & 50 & 10 & 1.810 & 1.809 \\
\hline 9 & 160 & 160 & 50 & 10 & 1.810 & 1.809 \\
\hline 10 & 160 & 160 & 50 & 10 & 1.810 & 1.809 \\
\hline 11 & 160 & 160 & 50 & 10 & 1.810 & 1.809 \\
\hline 12 & 160 & 160 & 40 & 8 & 1.879 & 1.862 \\
\hline 14 & 160 & 160 & 60 & 8 & 3.786 & 3.527 \\
\hline 15 & 160 & 160 & 60 & 12 & 2.637 & 2.740 \\
\hline 16 & 160 & 240 & 50 & 8 & 2.360 & 2.504 \\
\hline 17 & 160 & 240 & 50 & 12 & 2.254 & 2.100 \\
\hline 18 & 160 & 240 & 40 & 10 & 1.896 & 2.119 \\
\hline 19 & 160 & 240 & 60 & 10 & 2.598 & 2.842 \\
\hline 20 & 160 & 80 & 50 & 8 & 2.348 & 2.405 \\
\hline 21 & 160 & 80 & 50 & 12 & 2.777 & 2.537 \\
\hline 22 & 160 & 80 & 40 & 10 & 2.237 & 1.998 \\
\hline 23 & 160 & 80 & 60 & 10 & 3.520 & 3.302 \\
\hline 24 & 180 & 80 & 50 & 10 & 2.374 & 2.654 \\
\hline 25 & 180 & 160 & 50 & 8 & 2.535 & 2.805 \\
\hline 26 & 180 & 160 & 50 & 12 & 2.796 & 3.002 \\
\hline 27 & 180 & 160 & 40 & 10 & 2.551 & 2.195 \\
\hline
\end{tabular}


TABLE-3

ANOVA FOR RESPONSE SURFACE QUADRATIC MODEL

\begin{tabular}{cccccc}
\hline Source & Sum of squares & df & $\begin{array}{c}\text { Mean } \\
\text { square }\end{array}$ & F Value & $p$-Value \\
\hline Model & 9.4129 & 14 & 0.6723 & 7.3977 & 0.0003 \\
$\mathrm{~A}$ & 2.3055 & 1 & 2.3055 & 25.3671 & 0.0002 \\
$\mathrm{~B}$ & 0.0857 & 1 & 0.0857 & 0.9430 & 0.348 \\
$\mathrm{C}$ & 3.0797 & 1 & 3.0797 & 33.8850 & $<0.0001$ \\
$\mathrm{D}$ & 0.0555 & 1 & 0.0555 & 0.6103 & 0.4477 \\
$\mathrm{AB}$ & 0.2985 & 1 & 0.2985 & 3.2840 & 0.0915 \\
$\mathrm{AC}$ & 0.5808 & 1 & 0.5808 & 6.3907 & 0.0241 \\
$\mathrm{AD}$ & 0.1103 & 1 & 0.1103 & 1.2139 & 0.2891 \\
$\mathrm{BC}$ & 0.0843 & 1 & 0.0843 & 0.9270 & 0.352 \\
$\mathrm{BD}$ & 0.0716 & 1 & 0.0716 & 0.7874 & 0.3899 \\
$\mathrm{CD}$ & 0.4240 & 1 & 0.4240 & 4.6650 & 0.0486 \\
$\mathrm{~A}^{2}$ & 0.7366 & 1 & 0.7366 & 8.1047 & 0.0129 \\
$\mathrm{~B}^{2}$ & 0.4330 & 1 & 0.4330 & 4.7637 & 0.0466 \\
$\mathrm{C}^{2}$ & 1.6104 & 1 & 1.6104 & 17.7189 & 0.0009 \\
$\mathrm{D}^{2}$ & 0.6618 & 1 & 0.6618 & 7.2812 & 0.0173 \\
$\mathrm{Residual}$ & 1.2724 & 14 & 0.0909 & - & - \\
Pure error & 0 & 4 & 0 & - & - \\
$\mathrm{R}^{2}=0.88$ & Adeq precision $=10.89$ & - & - \\
\hline
\end{tabular}

characterized the actual relationship between the response and reaction variables.

Additionally, it could be deduced that $88 \%$ of the variability in the response was explained by the multiple regression model equation, whereas the remaining variation was ascribed to the residue. "Adeq Precision" was employed to measure the signal to noise ratio. A favoured ratio of 10.89 acted as an adequate signal as well as presented that this second-order polynomial model could be utilized to navigate the design space.

The $p$-value also mirrors the relative importance of the term related to that parameter. A $p$-value below 0.05 indicates that the model term is significant. A smaller $p$-value implies a greater significance for that term. From the results of the ANOVA, it was reasonably concluded that linear terms of reaction time $(\mathrm{C})$ and temperature $(\mathrm{A})$, as well as the quadratic term of reaction time $\left(\mathrm{C}^{2}\right)$, exhibited high statistical significances on the response yield, followed by nonlinear terms $\mathrm{AC}, \mathrm{CD}, \mathrm{A}^{2}, \mathrm{~B}^{2}$ and $\mathrm{D}^{2}$. Among these terms, reaction time $(C)$ exerted the most significant weight on the conjugated oil conversion. Nonetheless, there was no significant influence observed from the remainder of the terms. In addition, a coefficient with positive sign discloses that this term has synergistic effect on heightening the content of conjugated linoleic acid, whereas that with negative sign is an indicator of antagonistic effect. Logically, according to eqn. 3, the positive terms (A, $\mathrm{C}, \mathrm{AB}, \mathrm{AC}, \mathrm{AD}, \mathrm{A}^{2}, \mathrm{~B}^{2}, \mathrm{C}^{2}$ and $\left.\mathrm{D}^{2}\right)$ imposed promotion effects on the response yield. On the contrary, two linear terms (B and D) and three cross-product terms (BC, BD and CD) showed the opposite function.

Diagnostics of the empirical model: Fig. 6 extends the contrast on the response data estimated by the established polynomial model versus the measured results obtained from the $\mathrm{BBD}$ experiments. It is evident that the predicted values were satisfactorily in compliance with the actual values within the ranges inspected, which confirmed that the proposed model could accurately render the satisfied estimation for the response outcome.

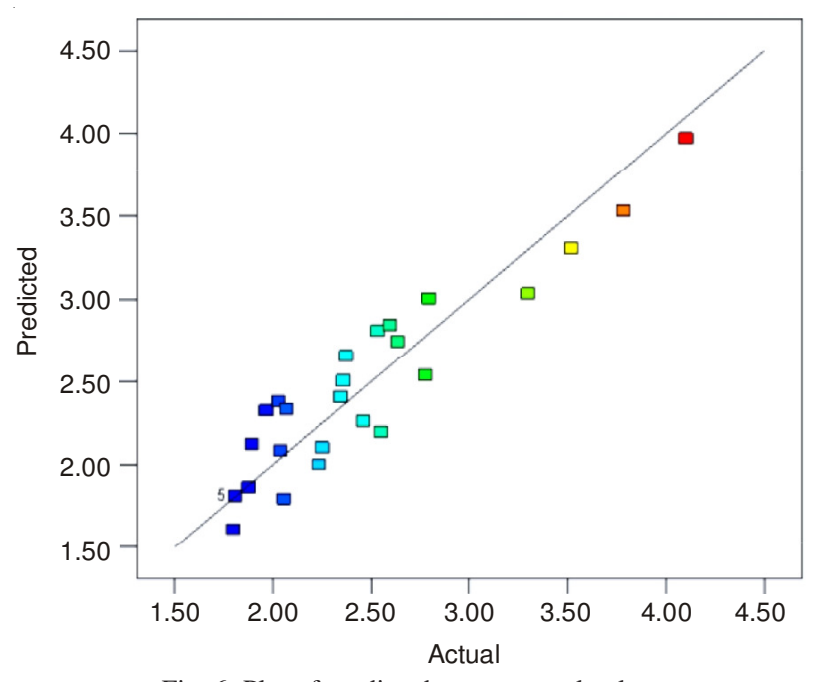

Fig. 6. Plot of predicted versus actual values

Fig. 7 furnishes the normal \% probability plot of residuals, grounded on internally studentized residuals, which was applied to check the difference between the experimentally observed and theoretically expected values. The general conclusion acquired from this graph was that the distribution of all the measured data resembled a straight line, suggesting that the error was insignificant and that the normality of the data was highly reasonable.

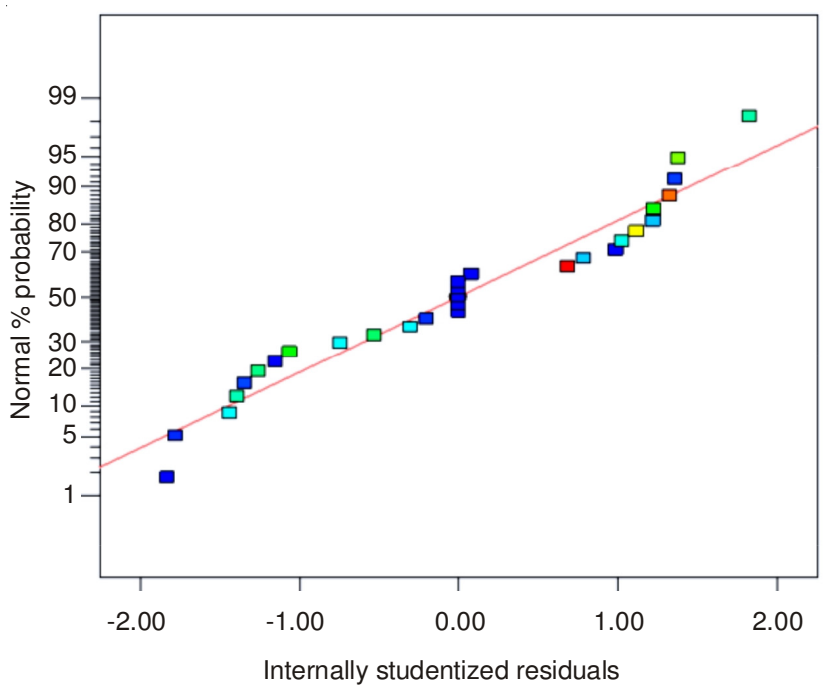

Fig. 7. Normal \% probability plot of residuals

Process optimization and validation of the quadratic model: The optimum conditions were obtained from the solution of the quadratic polynomial equation by Design Expert software. The best combination of variables supplied by the mathematical model was as follows: temperature of $179.96{ }^{\circ} \mathrm{C}$, ultrasonic power of $239.99 \mathrm{~W}$, reaction time of $1 \mathrm{~h}$ and catalyst loading of 8 wt. \%. Under such conditions, the maximum yield was predicted to be $4.949 \mathrm{mg} / \mathrm{mL}$.

Considering the actual operation possibility, however, the optimal values of factors were modified to be temperature of $180{ }^{\circ} \mathrm{C}$, ultrasonic power of $240 \mathrm{~W}$, reaction time of $1 \mathrm{~h}$ and catalyst loading of $8 \mathrm{wt}$. \%. On behalf of validating the proposed prediction, three independent replicates of oil-conjugated 
reaction were carried out under the modified optimum conditions. The average yield rate of conjugated linoleic acid $(\mathrm{n}=3)$ was measured to be $4.644 \mathrm{mg} / \mathrm{mL}$, which was satisfactorily close to the predicted value. Undoubtedly, the developed response surface model exhibited reliable predictability and adequate precision to estimate the conjugated linoleic acid yield.

\section{Conclusion}

In this investigation, the RSM sufficiently represented the real relationship between the dependent variable and process factors and successfully predicted the optimal reaction conditions. Besides, the experimental results confirmed that the ultrasonic-assisted oil-conjugated reaction using nickel catalyst was an environment-friendly, high-efficiency and economically feasible method to produce conjugated linoleic acid. The optimum conditions of the oil-conjugated reaction were temperature of $180{ }^{\circ} \mathrm{C}$, ultrasonic power of $240 \mathrm{~W}$, reaction time of $1 \mathrm{~h}$ and catalyst loading of $8 \mathrm{wt}$. \%, where the highest conjugated linoleic acid yield obtained was $4.644 \mathrm{mg} /$ $\mathrm{mL}$. Reaction time was found to impose the most significant impact on the conjugated linoleic acid content, followed by system temperature. In summary, there is a high untapped potential of low frequency ultrasound in combination with the solid catalyst for enhancing the conjugated linoleic acid production in the large-scale practical application.

\section{ACKNOWLEDGEMENTS}

The research was supported by the National Natural Science Foundation of China (Project No. 31071560).

\section{REFERENCES}

1. H.G. Park, W. Heo, S.B. Kim, H.S. Kim, G.S. Bae, S.H. Chung, H.-C. Seo and Y.J. Kim, J. Agric. Food Chem., 59, 984 (2011).

2. L.S. Meraz-Torres and H. Hernandez-Sanchez, Am. J. Food Technol., 7, 176 (2012).
3. R.R. Yettella, B. Henbest and A. Proctor, J. Agric. Food Chem., 59, 7377 (2011).

4. S.S. Saha, M. Patra and M. Ghosh, LWT-Food Sci. Technol., 46, 10 (2012).

5. H. Uehara, T. Suganuma, S. Negishi, Y. Uda, Y. Furukawa, S. Ueno and K. Sato, J. Am. Oil Chem. Soc., 85, 29 (2008).

6. N. Chorfa, S. Hamoudi and K. Belkacemi, Appl. Catal. A, 387, 75 (2010).

7. A.A. Hennessy, E. Barrett, R.P. Ross, G.F. Fitzgerald, R. Devery and C. Stanton, Lipids, 47, 313 (2012).

8. S.H. Chung, I.H. Kim, H.G. Park, H.S. Kang, C.S. Yoon, H.Y. Jeong, N.T. Choi, E.G. Kwon and Y.J. Kim, J. Agric. Food Chem., 56, 3311 (2008).

9. H.D. Hanh, N.T. Dong, K. Okitsu, Y. Maeda and R. Nishimura, J. Pet. Inst. (Japan), 50, 195 (2007).

10. X. Deng, Z. Fang, Y.-H. Liu and C.-L. Yu, Energy, 36, 777 (2011).

11. J.M. Dias, M.C.M. Alvim-Ferraz, M.F. Almeida, J.D. Mendez-Diaz, M.S. Polo and J.R. Utrilla, Fuel, 94, 418 (2012).

12. I. Worapun, K. Pianthong and P. Thaiyasuit, J. Chem. Technol. Biotechnol., 87, 189 (2012).

13. F.F.P. Santos, S. Rodrigues and F.A.N. Fernandes, Fuel Process. Technol., 90, 312 (2009).

14. F.F.P. Santos, L.J.B.L. Matos, S. Rodrigues, F.A.N. Fernandes, Energy Fuels, 23, 4116 (2009)

15. J.P.D.S. Fernandes, B.S. Carvalho, C.V. Luchez, M.J. Politi and C.A. Brandt, Ultrason. Sonochem., 18, 489 (2011).

16. D. Kumar, G. Kumar, Poonam and C.P. Singh, Ultrason. Sonochem., 17, 839 (2010).

17. H. Mootabadi, B. Salamatinia, S. Bhatia and A.Z. Abdullah, Fuel, 89, 1818 (2010).

18. X. Fan, X. Wang and F. Chen, Open Fuels Energy Sci. J., 4, 1 (2011).

19. B. Salamatinia, H. Mootabadi, S. Bhatia and A.Z. Abdullah, Fuel Process. Technol., 91, 441 (2010).

20. W. Chen, W.-P. Wang, H.-S. Zhang and Q. Huang, Carbohydr. Polym., 87, 614 (2012).

21. H.V. Lee, R. Yunus, J.C. Juan and Y.H. Taufiq-Yap, Fuel Process. Technol., 92, 2420 (2011).

22. A. Canals and M. Del Remedio Hernandez, Anal. Bioanal. Chem., 374, 1132 (2002).

23. T.J. Mason and J.P. Lorimer, Applied Sonochemistry, Wiley-VCH Verlag GmbH \& Co. KGaA; pp. 25-74 (2003). 